\title{
Copper and Lead levels in two popular leafy vegetables grown around Morogoro Municipality, Tanzania
}

\author{
B.E. CHOVE* , W. R. BALLEGU \& L.M. CHOVE \\ Department of Food Science and Technology, Sokoine University of Agriculture, \\ P.O. Box 3006, Morogoro, Tanzania
}

\begin{abstract}
A study was carried out to determine the levels of two heavy metals, Lead $(\mathrm{Pb})$ and Copper $(\mathrm{Cu})$, in two popular leafy vegetables grown around Morogoro Municipality in Tanzania. Vegetable samples of Pumpkin leaves (Cucurbita moschata) and Chinese cabbage (Brassica chinensis) were collected from three sites and analysed for their concentrations of the two metals using an Atomic Absorption Spectrophotometer. The three sites, namely Mazimbu, Kihonda and Towelo are located within a $10 \mathrm{~km}$ perimeter. The site selection was based on the anticipated levels of contamination of the water used for irrigation. The results showed that the levels $(\mathrm{mg} / 100 \mathrm{~g}$ dry weight) ranged from 0.885 to 1.39 for Copper and 0.05 to 0.315 for Lead. The levels of Lead and Copper varied between the vegetable varieties and from site to site. Vegetables from Mazimbu showed higher concentration levels of the two metals compared to the other sites in both varieties. Towelo vegetables had relatively low concentrations. There was a significant difference $(P<0.05)$ in levels of the two metals across the sites but there was no significant difference $(P>0.05)$ in the levels of Copper between the two vegetable varieties from all the three sites. There was a significant difference $(P<0.05)$ in the levels of Lead between the vegetable varieties. The levels of both Lead and Copper in the two vegetables were found to be below the maximum permissible levels recommended by FAO/WHO for the two metals in vegetables.
\end{abstract}

Keywords: Brassica chinensis, Cucurbita moschata, Copper, Lead, vegetables, Tanzania

\section{Introduction}

Vegetables are part of daily diets in many households forming an important source of vitamins and minerals required for human health. They also act as neutralising agents for acidic substances formed during digestion (Thomson \& Kelly, 1990). As human activities increase, especially with the application of modern technologies, pollution and contamination of the human food chain has become inevitable. Heavy metals uptake by plants grown in polluted soils has been studied to a considerable extent (Wong, 1996; Wong et al., 1996; Sukreeyaponse et al., 2002; Yusuf et al., 2003).

It has been established that heavy metals in soil are associated with various chemical forms that relate to their solubility, which directly bear on their mobility and biological availability (Xian, 1989). Heavy metals in soluble form have high relation to their uptake by plants (Miller \& McFee, 1983). Vegetables can absorb metals from the soil as well as from deposits on parts of the vegetables exposed to the air from polluted environments (IOCCC, 1996; Haiyan \& Stuanes, 2003). In recent years, the amount of air pollution caused by Lead has increased considerably due to industrial and car emissions, affecting plants and watercourses (Puchades et al., 1989; Igwegbe et al., 1992; Wyatt et al., 1998; Banuelos \& Ajwa, 1999). In some cases even packaging materials have been found to be sources of heavy metals found in foodstuffs
(Conti, 1997). Surface applied liquid sewage sludge can remain on grass leaf surfaces, leading to enhanced direct intake of potentially toxic elements by the stock (Aitken, 1997).

In many developing countries it is a common practice to grow vegetables along banks of rivers passing through urban centres. Waters of such rivers have often been reported to be polluted by heavy metals (Mashauri \& Mayo, 1990; Kashem \& Singh 1999; Othman, 2001). The extent of absorption of the elements by the plant depends on, among other things, the nature of the plant, chemical constitution of the pollutant, concentration of the element in the soil, $\mathrm{pH}$ and the interaction with other metals (Zurera et al., 1989). Chronic low-level intakes of heavy metals have adverse effects on human beings and other animals due to the fact that there is no effective mechanism for their elimination from the body (IOCCC, 1996; Bahemuka \& Mubofu, 1999). Metals such as Lead, Cadmium, Mercury and Copper are cumulative poisons. They have been reported to be exceptionally toxic (Ellen et al., 1990). Lead has been associated with intoxications leading to problems in the kidney and liver, the central nervous system, reproductive organs and anaemia (IOCCC, 1996). Although Copper is an essential trace element in the functions of the human body, chronic and excessive intake has been linked with digestive tract problems and cirrhosis of the liver (Oskarsson, 1989; Abdulla \& Chmielnicka, 1990).

The present study aimed at establishing the levels of contamination of Lead and Copper in two popular

\footnotetext{
"To whom correspondence should be addressed. E-mail: bchove@suanet.ac.tz
} 
leafy green vegetables, Chinese cabbage and Pumpkin leaves, which are grown and consumed in and around the Morogoro Municipality in Tanzania.

\section{Materials and methods}

\section{Study area}

This study was carried out in Morogoro Municipality $\left(6^{\circ}, 49^{\prime} \mathrm{S}, 3^{\circ}, 40^{\prime} \mathrm{E}\right)$ in Tanzania. There exist a few manufacturing industries around the town. Three locations, namely, Mazimbu, Kihonda and Towelo were selected for the study. Vegetable samples were purchased from the three sites, which were selected basing on the anticipated contamination of the water used for irrigation. Mazimbu is irrigated using a watercourse passing by a metallurgical factory; Kihonda is located near a residential estate and a wastewater treatment area of a leather and textile industrial estate; and Towelo is irrigated with water flowing down a slopping catchment area of a surrounding Eastern Arc mountain range.

\section{Vegetables}

The edible portions for the two vegetable varieties (Pumpkin leaves and Chinese cabbage) were randomly purchased on site from the cultivated areas. Sampling was carried out over a period of two months during the dry season (October-November) during which the plots were irrigated. Two samples of each vegetable were collected fortnightly making a total of eight samples of each vegetable (16 per site, 48 in total for the three sites) by the end of the two months period. All samples were collected and stored in individual polythene bags before being brought to the laboratory for analysis.

\section{Vegetable sample preparation}

The method used by Bahemuka \& Mubofu (1999) was followed with some minor modifications. The collected vegetable samples were all washed thoroughly with distilled water to remove surface pollutants. The stalks were removed from the leafy green vegetable portions. All samples were then sliced into small pieces and left to dry on paper for about 2 hours to eliminate excess moisture. Each sample was weighed and dried in an oven at $80^{\circ} \mathrm{C}$ to constant weight. Each dry sample was ground in a mortar until it could pass through a 65-mesh sieve.

The samples were then stored in clean dry stoppered glass containers. A dry ashing technique was employed followed by an atomic absorption spectrophotometric analysis. One (1) g of the ground sample was accurately measured in a crucible. The crucible with its contents was placed in a muffle furnace and ashed at $450^{\circ} \mathrm{C}$ for 12 hours. The ash was digested with $5 \mathrm{ml}$ of $20 \%(\mathrm{v} / \mathrm{v}) \mathrm{HCl}$ solution. The residue was filtered into a volumetric flask using a Whatman No. 41 filter paper and the solution was made to the $50 \mathrm{ml}$ mark with deionised water.
A Unicam 919 Atomic Absorption Spectrophotometer (Cambridge, UK) was used to analyse the samples. All stock standard solutions of Lead and Copper were prepared as per instruction manual of Unicam 919. A standard air-acetylene flame was used in all determinations. A wavelength of 283.3 $\mathrm{nm}$ for Lead and that of $324.8 \mathrm{~nm}$ for Copper was used while the corresponding slit widths were $100 \mu \mathrm{m}$ and $45 \mu \mathrm{m}$ respectively. The lamp current was $10 \mathrm{~mA}$ for both metals.

\section{Data analysis}

Analysis of variance (ANOVA) of the means of the detected quantities of each metal was carried out using the SAS (1989) statistical software.

\section{Results}

There was no significant difference in the concentrations of Copper in both vegetables from Kihonda and Towelo. Samples from Mazimbu showed significantly higher concentrations although there was no significant difference between the levels in the two vegetables from this site (Figure 1).

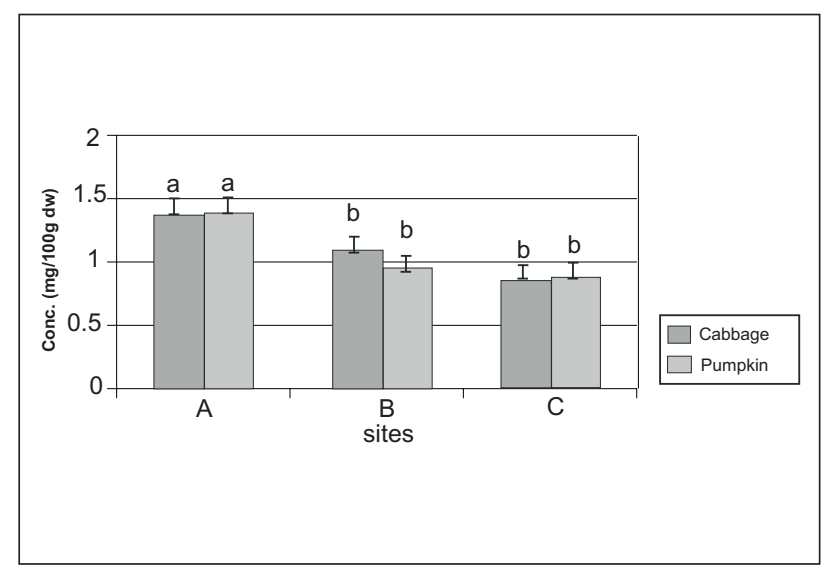

Figure 1: The concentration of Copper in cabbage and pumpkin in Mazimbu (A), Kihonda (B) and Towelo (C). Concentrations that do not bear the same letter are significantly different $(\mathrm{P}<0.05)$. The error bars represent standard deviations

Chinese cabbage had higher values of Lead compared to pumpkin leaves from Mazimbu and Towelo (Figure 2). There was no significant difference in Lead concentrations in samples from Kihonda. As a general observation, samples from Towelo showed lower concentrations in both metals in the two vegetables. Both vegetables from Mazimbu had the highest concentrations of the two metals. The range of concentration varied from 0.885 to $1.39 \mathrm{mg} / 100 \mathrm{~g}$ dry weight for Copper and from 0.05 to $0.315 \mathrm{mg} /$ $100 \mathrm{~g}$ dry weight for Lead. 


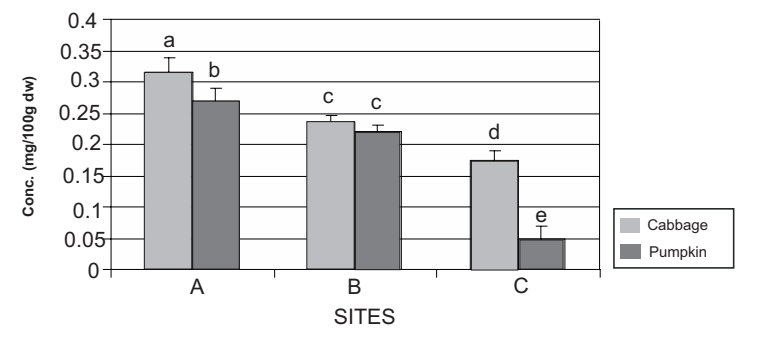

Figure 2: The concentration of Lead in the two vegetables for the three sites. Concentrations that do not bear the same letter are significantly different $(\mathrm{P}<$ 0.05). The error bars represent standard deviations

\section{Discussion}

The contents of both Lead and Copper reported in this study are generally lower than the permissible levels by FAO/WHO in vegetables. These are $0.5 \mathrm{mg} / 100 \mathrm{~g}$ dry weight for Lead and $4.0 \mathrm{mg} / 100 \mathrm{~g}$ dry weight for Copper. However, the joint FAO/WHO Expert Committee for Additives and Contaminants (JECFA) (Codex Alimentarius Commission, 1995) has reduced the value it had provisionally specified for adults in 1974, for tolerable Lead consumption per week (provisional tolerable weekly intake - PTWI) from $0.05 \mathrm{mg} / \mathrm{kg}$ body weight to $0.025 \mathrm{mg}$. The corresponding PTWI for Copper is $3.5 \mathrm{mg} / \mathrm{kg}$. The reason for the reduction is that research has revealed further harmful potentials in Lead. This specification taking into account the body weight implies that children are more vulnerable to the effects of Lead than adults.

Our study has shown that the concentrations of Copper in both vegetables from the two sites of Kihonda and Towelo were similar. However, samples from Mazimbu showed significantly higher concentrations. It has been reported that Copper release rates from contaminated soils are comparatively lower than those for Lead and some other heavy metals (Wong et al., 1996; Sukreeyapongse et al., 2002). This high tendency of added Copper to remain in the soil could be the main controlling factor for its uptake rates by plants.

Interestingly, Chinese cabbage had higher Lead concentrations compared to Pumpkin leaves from Mazimbu and Towelo. Recently, Wong et al (1996) reported that Chinese cabbage picks up Lead more readily compared to other heavy metals such as Cad- mium, Copper, Nickel and Zinc. It can be stated that the site of growth noticeably influences the heavy metal uptake by the two vegetable varieties. Samples from Towelo had lower concentrations in both metals in the two vegetables. This is most likely to be due to the fact that the irrigation water for this site does not pass near any industrial area and it does not go across areas of high levels of human activity. It is thus free from industrial effluents and also reasonably free from domestic drainage, hence the relatively lower levels of the two heavy metals. Contamination of the samples from this site is then most probably from the parent materials making up the soil at this location.

The concentrations of the two metals in both vegetables from Mazimbu were comparatively higher than those from the other two sites. As observed earlier, many rivers passing through urban areas are polluted with heavy metals. It has been reported that the major sources of these heavy metals, including Copper and Lead, are industrial effluents and indiscriminate disposal of domestic or sewage directed to the rivers untreated or partially treated (Bahemuka \& Mubofu, 1999). Sewage and industrial waste streams from the metallurgical factory are likely to find their way to the nearby watercourse, which is subsequently used for irrigation of vegetable gardening plots in this site. On the other hand, contamination at Kihonda can be attributed to the activities by the leather and textile factories and the residential estate. Chromium, Lead, Mercury and some gases are typical toxicants from such factories (Mashauri \& Mayo, 1990).

As regards to the metal uptake rates for the two vegetable varieties it is discernible that the rate is metal specific. While Copper was taken at almost a similar rate by the two vegetables, the situation was different in the case of Lead. From the findings of our study it is evident that the uptake of Copper and Lead by the two vegetables is influenced by the soil on which they are grown. Although the concentrations of the Copper and Lead established for the vegetables are lower than those permitted by FAO/WHO, what matters in the long run is the quantities consumed and the frequency of intake. As already noted, there is a cumulative effect on sustained intake of heavy metals, as they are not easily removed from the body. Many rural and urban low-income families in Tanzania consume large quantities of vegetables on a daily basis and this exposes them to the health risks associated with heavy metals ingestion.

\section{Acknowledgements}

The authors wish to acknowledge the support by the Government of Tanzania, through the Ministry of Science, Technology and Higher Education for financing this study. 


\section{References}

Abdulla, M. \& Chmielnicka, J. (1990) New aspects on the distribution and metabolism of essential trace elements after dietary exposure to toxic metals. Biological Trace Element Research 23, 25-53.

Aitken, M.N. (1997) Short-term surface adhesion of heavy metals following application of sewage sludge to grassland. Grass and Forage Science 52, 73-85.

Bahemuka, T.E. \& Mubofu, E.B. (1999). Heavy metals in edible green vegetables grown along the sites of the Sinza and Msimbazi rivers in Dar es Salaam, Tanzania. Food Chemistry 66, 6366.

Banuelos, G.S. \& Ajwa, H.A. (1999) Trace elements in soils and plants: an overview. Journal of Environmental Science and Health (A) 34, 951-974.

Codex Alimentarius Commission (1995) Joint FAO/ WHO Expert Committee for Food Additives and Contaminants (JEFCA), Discussion Paper on Lead (CX/FAC 95/18), March 1995.

Conti, M.E. (1997) The content of heavy metals in food packaging paperboards: an atomic absorption spectroscopy investigation. Food Research International, 30, 343-348.

Ellen, G., Loon, J.W. \& Tolsma, K. (1990) Heavy metals in vegetables grown in the Netherlands and in domestic and imported fruits. Zeitschrift fur Lebensmittel-Untersuchung und Forschung 190, 34-39.

Haiyan, W. \& Stuanes, A. (2003) Heavy metal pollution in air-water-soil-plant system of Zhuzhou City, Hunan Province, China. Water, Air and Soil Pollution 147, 79-107.

Igwegbe, A.O., Belhaj, H.M., Hassan, T.M. \& Gibali, A.S. (1992) Effect of highway's traffic on the level of Lead and Cadmium in fruits and vegetables grown along the roadsides. Journal of Food Safety 13, 7-18.

IOCCC (1996) International Office of Cocoa, Chocolate and Sugar Confectionery. Paper on the position of IOCCC on heavy metal contamination in the confectionery industry. April 1996, Belgium. (http:// www.international-confectionery.com/pdf/ Metals.pdf.)

Kashem, M.A. \& Singh, B.R. (1999) Heavy metal contamination of soil and vegetation in the vicinity of industries in Bangladesh. Water, Air and Soil Pollution, 115, 347-361.

Mashauri, D.A. \& Mayo, A. (1990) The environmental impact of industrial and domestic wastewater in Dar es Salaam. In: M.R Khan and Gijzen (eds), Environmental Pollution and its Management in East Africa. University of Dar es Salaam, Tanzania. Pp 23-32.

Miller, W.P. \& McFee, W.W. (1983) Distribution of Cadmium, Zinc, Copper, and Lead in soils of industrial North-western Indiana. Journal of Environmental Quality 12, 29-33.

Oskarsson, A. (1989) Health hazard of high concentrations of Copper in drinking water. Var Foeda 41, 257-259.

Othman, O.C. (2001) Heavy metals in green vegetables and soils from vegetable gardens in Dar es Salaam, Tanzania. Tanzania Journal of Science 27, 37-48.

Puchades, R., Maquieira, A. \& Plantá, M. (1989) Rapid digestion procedure for the determination of Lead in vegetable tissues by Electrothermal Atomisation Atomic Absorption Spectrometry. Analyst 114, 1397-1399.

SAS (1989) SAS User's Guide. SAS Inst., Inc., Cary, NC.

Sukreeyapongse, O., Panichsakpatana, S. \& Hansen, H. (2002) Transfer of heavy metals from sludge amended soil to vegetables and leachates. Paper presented at the $17^{\text {th }}$ World Congress of Soil Science (WCSS), $14^{\text {th }}-21^{\text {st }}$ August 2002, Thailand. Symposium No 29, paper No. 1969.

Thomson, H.C. \& Kelly, W.C. (1990) Vegetable Crops

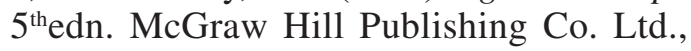
New Delhi.

Wong J.W. (1996) Heavy metal contents in vegetables and market garden soils in Hong Kong. Environmental Technology 17, 407-414.

Wong, J.W., Li, G.X. \& Wong, M.H. (1996) The growth of Brassica chinensis in heavy metal contaminated sludge compost from Hong Kong. Bioresource Technology 58, 209-313.

Wyatt, J.C., Fimbles, C., Romo, L., Méndez, O. \& Grijalva, M. (1998) Incidence of heavy metal contamination in water supplies in Northern Mexico. Environmental Research (A) 76, 114119.

Xian, X. (1989) Effect of chemical forms of Cadmium, Zinc, and Lead in polluted soils on their uptake by cabbage plants. Plant and Soil 113, 257-264.

Yusuf, A.A., Arowolo, T.A. \& Bamgbose, O. (2003) Cadmium, Copper and Nickel levels in vegetables from industrial and residential areas of Lagos City, Nigeria. Food and Chemical Toxicology 41, 375-378.

Zurera, G., Moreno, R., Salmeron, J. \& Pozo, R. (1989) Heavy metal uptake from greenhouse border soils for edible vegetables. Journal of the Science of Food and Agriculture 49, 307314. 